\title{
The Concept of the Future and the New Paradigm of the Fifth Spiral: State, Business, Science, Society and Informatization
}

\author{
Orazaly Sabden ${ }^{1}$
}

Received : May 16, 2018 Revised: August 29, 2018 Accepted: September 30, 2018

\begin{abstract}
At a turn of the third millennium the world storms and quickly changes. It became difficult to expect what expects us tomorrow. The most important are questions of recovery from the crisis and rescue of mankind from forthcoming global changes: warming of climate, water and food problems, social, economic and political conflicts that are shaking the world and other various cataclysms, accidents, negative processes. It puts before mankind the problem which never solved by our civilization. All this is caused by ignoring of objective economic laws, laws of wildlife and also by violation of cyclic development management's laws. In article the concept of strategy of mankind's survival in XXI and next centuries, the principles of creation of planetary house of universal civilization for post-industrial world based on spirituality scientific and technological revolutions, ecology, space exploration, economy and world safety are considered. Introduction of uniform universal measurement of currency for the whole world in the form of "power" is offered. Important aspect of a research is theoretical postulate on integrated innovative society. The author puts forward a new paradigm of government on a basis of 5 spirals. The basic model of forced development of small and medium business, including 9 projects, is developed.
\end{abstract}

Keywords: Business, Science, Society, Informatization, Spirituality.

JEL Classification Code: B22, E12, F63, H10, H75.

\section{Introduction}

The world is in a turbulent movement, and nothing can be foreseen. All world thinkers, politicians and practitioners are still powerless to do anything to see the light (civilizational development) at the end of the tunnel. Put forward a new idea of building an integral innovation society with a spiritual component. Since in the pursuit of capital the whole world has missed or has obviously insufficient attention paid to spirituality, morality, human values of civilizational society. It is necessary to build a new integral innovative society with a human face, relying on the whole evolutionary historical process, on the experience of all formations (primitive communal, slave-owning, feudal, capitalistic, socialist).

1 First Author and Corresponding Author. Chief Scientist, Institute of Economics of the Ministry of Education and Science of the Republic of Kazakhstan [Postal Address: 29 Kurmangazy Street, Almaty 050010, Republic of Kazakhstan] Tel.: 8(727)2721219, E-mail: osabden@mail.ru
In place of capitalism and socialism, a new integral innovation society, including the best features of these formations, is coming. In our opinion, this is the new paradigm for the development of world civilization. This idea, however, in a different format began to be realized in China, synthesizing the best features of capitalism and socialism. As a result, triumphant successes, but in strategic terms, China's democracy is still ahead. Whereas Scandinavian countries began to implement this idea of integral society with an emphasis on the mechanisms of democracy. Perhaps this is the most advanced system and convergent path in terms of democracy and civilizational development.

For a better vision of the future world, the author developed a concept for the survival strategy of mankind in the 21st and later centuries, the principles of building a planetary home for the universal civilization of the postindustrial world based on spirituality, scientific and technological revolutions, ecology, space exploration, economics and world security. In order to implement this theoretical postulate on an integral innovation society in practice, the author proposes new paradigm for governing 
the state on basis of 5th helix; effective interaction of the state, science, business, society and information borrowing. Below we briefly outline the main provisions of future concept and new management paradigm based on the 5th helix.

\section{Theoretical Model I: The Concept of the Future}

Conventional efforts to overcome global challenges become less and less efficient while a failure to act promptly may lead to unpredictable and irreversible consequences which are potentially devastating for all of humanity. The consideration of problem has to be based on contours of constructed planetary house of universal civilization (Figure 1).

The planetary house of universal civilization and the future new waves in scientific and spiritual revolution, will be founded on combination of six key Basic Elements of transition to post-industrial civilization, such, as:

1. Humanization of world community taking into account logic of world history's development.

2. New scientific and technological revolution, technological ways (VI-VII-TU).

3. Ecology and stabilization of world power consumption.

4. Space exploration, space energy and resources of Solar system.

5. World safety.

6. Transition from market economy to innovative economy for post-industrial civilization.

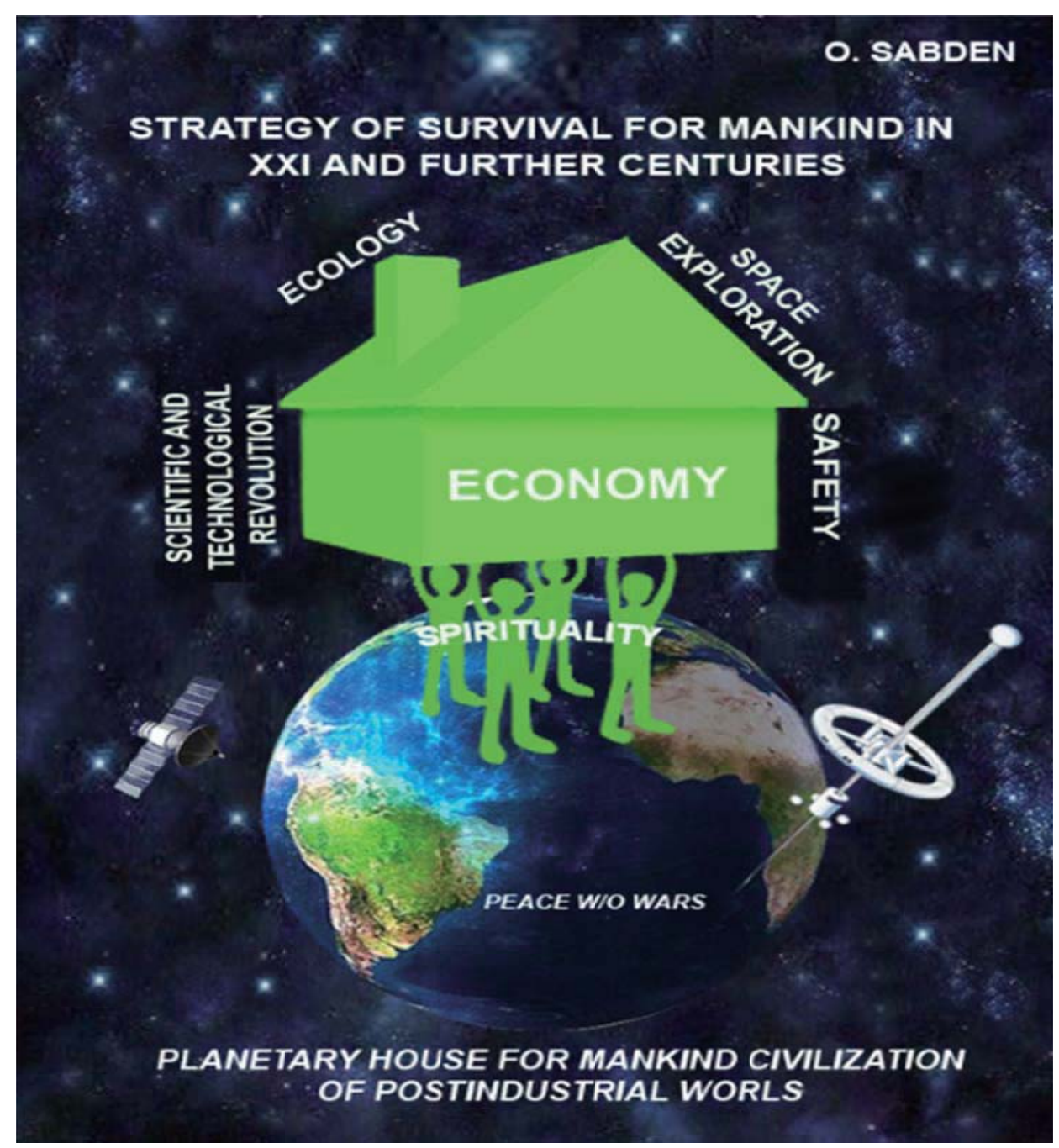

Figure 1: The planetary house of universal civilization 
For the first time within conditions of globalization and crises there is an understanding of historical need of coordination of all aspects of scientific and technical, ecological, space, spiritual, economic security as uniform system of providing universal civilization and transition from biosphere into noosphere with preservation of development of the world not only on Earth, but also in space.

Main objective of presented megaproject is development of conceptual provisions on formation of new transitional model to post-industrial civilization basing on components of transition offered by us to post-industrial world. Conceptual idea is that more than 200 states on a planet turned to members of one family and peacefully lived under a roof of uniform planetary house of universal civilization (see Figure 1). All six Basic Elements of civilization genotype are in first quarter of $X X I$ century endure deep transformation in course of changing industrial world civilization into post-industrial one. Radical difference of this megaproject is that if before research and results of scientists, geniuses of science, Nobel Prize laureates were based on achievements of stunning opening and achievements in certain important spheres, for example physics, chemistry, medicine and physiology, literature, peacemaking and economy, in this monograph author for the first time in the world tried to consider on the basis of system approach all six basic components of transition to post-industrial civilization as unit of interconnected spiritual and scientific-technological process (Figure 1).

Creation of such house for civilization on basis of causal communication with offered six blocks allows revealing stability and logic of world historical development in new conditions of post-industrial civilization. The most important is that the house of civilization is basing on hands of people, on so-called spirituality of human development, and, naturally, everything that of performing - performs for people, for reaching satisfaction and ensuring quality and level of their life. For the first time the thesis that from economical point of view production should be focused not on satisfaction of material and spiritual needs of the abstract consumer, buton consumption of the specific person. Therefore indoors on power of economic base spirituality, wellbeing, friendship of the people, harmonious developments of humanity are reigning. And at last, service for reaching future peaks, instead of a mammon, i.e. to wealth is carried out. If world on basis of planetary cooperation of nations and ethnos adopts everything achievement, it will rescue a human civilization and big assistance to creation of I type of the Planetary civilization will be rendered. The stated suggests idea to think of formation of new global control system structure by world not to allow global crises, accidents, climate warming, and other negative processes and threats which can lead a human civilization to the end.

In our opinion, it is necessary to change views on market economy, the innovative economy of post-industrial civilization comes after that. It is based on new knowledge, science and high technologies, competitiveness of human capital with all ranges of spirituality upgrading and updating of values' system. Further briefly we will stop on each of six blocks

\subsection{Humanization of World Community}

The global crisis continues. The roots of this crisis are systemic ones, and they are generally known. Among them, the key one is humanistic worldview approach. In this regard, the highest priority is given to solving the problems of humanizing society as the spiritual basis of the world order. The national idea, focused on consciousness of people, is necessary for states (Stiglitz, 2009).

World religions very poorly protect the population from moral decomposition and crime, don't bear original spiritual revival and a national unification, create only imitation of it. All this influences national security of the world. Though as a whole the religion always played and plays a rod role in attempts to find support by means of which it is possible to move heaven and earth and not to drop out of it. Who will deny that religiousness doesn't do believers happy? It is probably correct that spiritual representatives of world always first of all put forward ideas promoting awakening of consciousness, to its release from stereotypes, and only then recommended to apply technologies improving physical body without which the consciousness can't realize completely itself and exist in a material world.

In an unstable century of globalization the idea about humanization of society can become a factor of unification of people and states. After implementation of listed actions by revival and use of centuries-old historical values there will be opportunities of global changes in spiritual and cultural development of mankind. It will be a big step maintaining honor of society not to become stagnation sources. The main task of humanization ideas is to change thinking of person, his consciousness according to requirements of new civilized society of XXI century. A lot of things should be done on settling of disagreements in the world.

Restoration of harmonious development of society and nature in XXI century is possible by elimination of large shortcomings - instead of production and development of not infinite raw material resources and minerals it is necessary to develop the new vision, the new ideas, new projects of development. All stated above testifies that in world development there comes such moment, the truth 
moment, when there will be need of elaboration new global strategy of world order. Seems that it is necessary to begin with development the correct state ideology directed on preservation of moral, spiritual cultural values and traditions.

Key components of society's humanization and spirituality revival taking into account development of world history are following (see Figure1):

- history of past, present and future;

- change of world psychology;

- revival of spiritual and moral values, world religion, including Islam, Christianity, Buddhism, Confucianism, etc.;

- harmonious development of society;

- creative development of human capital in a sharp decrease in the number of people in the world;

- spiritual revolution in XXI century.

To answer how global problems are to be solved, time came under the auspices of the UN to accept Concept of new spiritual and ideological doctrine of universal development of the world. It will provide lifting of spiritual forces of nations and nationalities of the world and their social and economic progress. Finally there will be a transition to a post-industrial paradigm of spiritual development. As an example briefly we will state idea of revival spiritual beginning in one of the Euroasian regions. We are speaking about creation of the new spiritual and technological cluster "Turkestan Valley" (it is represented in form of uniting West and East on Great Silk Way of regional model of the world order, new spiritual, technological development and international security) (Sabden, 2015).

\subsection{Scientific and Technological Revolution}

Humanity is now making its first steps into a new, postindustrial socially-oriented civilization whose main driver is the progress in science and technology. Most of the developed nations of the world, guided in their endeavor by the Theory of Long Waves, are now completing the fifth technological cycle and are actively engaged in building the foundation for the sixth techno-cycle. The core factors of the next technological cycle will be biotechnologies, nanotechnologies, genetic engineering, information and communication networks, artificial intelligence and space technologies. Innovation seems to be the only appropriate solution to the global crisis, which means developing strategies for innovative breakthroughs through large-scale international development programs tailored for specific clusters.

Later on, after the VI techno-cycle has been fully expressed (possibly by 2050), the global economy will go into the next long-wave technological cycle at a new level of the post-industrial civilization. Considering these circumstances, together with states G8, G20 it is desirable for structural divisions of the United Nations to develop joint structure on accumulation of all knowledge of world history's development, to create intellectual product from mankind origin about one today, i.e. to have strongest base of scientific and technical information which will be necessary for development of any megaproject, assistance on development and transfer of new knowledge. It might be correct to consider correct structural divisions of United Nations together with the states G8, G20 expected scenarios of development of international problems in XXI century for receiving corresponding decision and anticipatory measures.

The solution of such complicated task for developing countries, for CIS countries and for Kazakhstan is impossible without introduction of new technologies based on critical technologies. According to international standards, every four years the list of critical technologies should be adjusted. In our view, it is necessary to introduce number of changes into critical technologies, recognizing the development of social and humanitarian cluster as one of the priority directions in modern conditions. The rises of spiritual and cultural values in all its manifestations are to be among priorities of the state.

On the basis of noted conceptual approach, we are proposing to add to list of priority areas t the new direction "Technologies of the social and humanitarian direction", which include four critical technologies for the development of Kazakhstan society:

- Intellectual and spiritual culture of the nation;

- New knowledge of development for modern society;

- Human needs, building human capital;

- Formation of new integrated socio-economic model of innovative development (formation and implementation of the 5th helix).

The XXI century of civilized development sets other tasks, i.e. ensuring competitiveness in the global technology markets with definition of priorities in science and technology in the world space, as well as compilation of list of critical technologies and mechanisms for their implementation. It is especially important to intensively develop such breakthrough directions of innovative development as new materials (composites), information and communication technologies, biotechnologies, take new world trends - Internet technologies with connection of industrial Internet, new M2M technologies.

The core of new scientific and technological revolution in near future will be information technologies, which are the basic element of post-industrial world. In this regard, it is very important for developing countries and the Republic of 
Kazakhstan to accelerate the creation of single information belt, information infrastructure that ensures accessibility of any information and information technology for development of innovative economy. It is necessary to form information economy as a new sector (branch) of economy. Thus, it is necessary to raise the question of expediency of forming an innovative socio-economic structure as general economic category, taking into account both technological, and economic, and social and humanitarian components. On the basis of a systemic approach, through deep institutional changes, the accelerated development of SMEs, the creation of single information belt, the emergence of innovative economy, the developing country can be made leap and became closer to developed countries.

\subsection{Ecology and Stabilization of World Power Consumption}

The biosphere of Earth has huge resources which are used by mankind, but are limited and can be exhausted by the end of current century. Mankind closely came nearer "to a non-return point", especially in development of processes of global ecological disaster. In this regard preservation of our planet global ecosystem with rational use of natural and resource capacity of Earth is especially actual in XXI century. By estimates of some scientists-experts if mankind doesn't take urgent measures for preservation of planet ecosystem, then ecological death of mankind can already come in XXI century, i.e. on first phase - a phase of global ecological disaster (Subetto, 2013). As known scientist in the field of the biosphere $\mathrm{N}$. Moiseyev claims, there comes probability of stability loss for biosphere of complete system and, probably, parameters of biosphere will be improper for human life (Moiseyev, 1999).

As for observance of the Kyoto Protocol on $\mathrm{CO}_{2}$ till 2020, leading countries of the world -USA, People's Republic of China, EU, India and Russia don't carry out it. Therefore time came to take radical measures for reduction of emissions, greenhouse gases to safe level. In this plan neither Copenhagen conference (2009), nor conference of UN on sustainable development "Rio +20 " didn't help to solve matter considerably (2012). Probably, first, it is necessary to enter rigid sanctions and tax regulations on $\mathrm{CO}_{2}$ emissions, secondly, to create global power ecological fund and as a whole to stimulate this process. Restriction of global warming to $20 \mathrm{C}$ was confirmed with UN in declaration adopted by Copenhagen international conference on climate change in 2009. But, unfortunately, even UN - the most authoritative organization, can't actively interfere and is powerless before such world authorities, as USA, People's Republic of China, etc. It testifies that status of UN is insufficient for solution of global problems, and also there is no political will of heads. And when there will come ecological crisis, it will be late to undertake something.

So, conclusion is that considering new conditions of globalization, crises, global cataclysms, geophysical accidents, climate warming, food crisis, transition to new technological ways, and also approach of period of space development and safety in space and on Earth etc., it is necessary to reform radically in shortest time all UN system, having moved its headquarters on other continent. For implementation of it, it is necessary to create working group of experts, analysts, independent scientific organizations, strong minds of world for preparation of offers on UN reforming. Perhaps, it is time to create under UN new body - Supreme council of wise men of world.

The era of energy economy begins, i.e. saving energy for normal, comfortable, safe use by its humanity, which excludes various disasters and ecological crisis. Very fatal there is exit search from impasse of "Death Valley" by means using noosphere power ecological way of production and consumption of solar energy, hydrogen fuel and energy of magnetism. It will be new paradigm of power consumption, new power ecological revolution of second quarter of XXI century which is based on development of $\mathrm{VI}$ technological way. To carry out this revolutionary jump, huge efforts of partnership of world civilization are necessary.

\subsection{World Development of Space, Space Energy and Resources of Solar System}

Ever since the beginning of the space exploration era, the military circles of every superpower have contemplated military applications for space technologies. Prof. Vladimir Vernadsky puts moral values way above material ones, whereas in the reality of the 'technological man' of the present day this value scale is reversed (Vernadskiy, 1991). Not surprisingly the fantastic predictions made many years ago by Leonardo da Vinci, Jules Verne, Benjamin Franklin and the Marquis de Condorcet now have become an everyday reality. In the nearest future solar power and hydrogen power will dominate the energy balance, while their market share today is only $0.5 \%$ of the total human consumption).

We don't know, whether is and what civilization in space or on other planets. Therefore having get exit to space, mankind as sample of land civilization has to bear with itself intellectual, spiritual and moral, humanistic values adequately to meet possible civilizations of other planets. It is unreasonable to connect sustainable development with continuous use of non-renewable natural resources, but with use of renewables, resources of noosphere it is possible to approach solution of main problem of sustainable development of mankind reasonably. 
Development of humanity in XXI century on basis of efficiency, competitiveness of economy has to come to following stage -stage of consolidation, cooperation, socialization and society humanization, i.e. the joint solution of global problems of interstate, intercontinental, interplanetary balance. Only such way survival of mankind becomes planetary task -problem of association of efforts of all people of world on basis of mutual respect, principles of social justice, refusal of wars and violence, establishment of general harmony on planet Earth. In thirties of XXI century when programs of commercialization of space will be developed, when obtaining energy from space it is expedient to reach the agreement of leading countries of world in advance. All this requires legislative regulation of the world parameters.

\subsection{World Safety}

World safety on basis of developing prevention system of global threats, crises, accidents, etc. As development of world history, any achievement in economic, scientific and technological spheres, in space exploration and other spheres not significantly without ensuring world and regional security testifies (Kreativnyy kapitalizm, 2010). World crisis showed that future new knowledge, scientific, information and technological changes, social and public transformation will strongly and quickly change the world. There came an era of global scientific progress where rates of knowledge of the world will multiply increase. Race of arms, militarization of USA, Russia, People's Republic of China and other countries can lead to third world war between 2020-2030 that can potentially destroy everything on planet. If this course isn't changed in time, it is known that expects us in near future is new round of war.

Better these huge amounts of money of country would spend for joint projects on space exploration, ecology improvement, security measures on fight against climate warming etc. These means need to be used for rescue of general planetary house of all mankind (see figure 1). Considering that planetary economy arises, economy of new knowledge, instead of race by arms has to be new criterion of development of superstates. Enormous force terrorist attack is prepared by environment. Climatic revolution on threshold. This accident is much closer, than it was possible to assume, and in the next 20 years it will be costs life to million people (Subetto, 2013).

In this connection, we consider the security problem as integral system of economic, social, environmental, innovation, food, demographic, scientific and technological, information, energy, space and other types of security. Only comprehensive safety assurance will yield sustainable result. It is necessary to develop basic principles of ensuring security, maximum permissible critical values and indicators characterizing all types of national security, which are covered in our book (Stiglitz, 2009).

\subsection{Transition from Market Economy to Innovative Economy of Post-Industrial Civilization}

As it was specified earlier, prospects of development of world economy contact formation of innovative economy which can be considered as most important direction of development of world in the XXI century. Globalization and world crisis showed that many theories, including a Keynesian one and monetarism, are right only at certain assumptions and revolution waves. Paying tribute to views of these scientists, founders of innovation and competitiveness, in practice in pursuit of excess profit world multinational corporations controlling more than half of world gross domestic product, often forget about other components, for example about human factor, moral, spirituality, sharp stratification of society, society greening etc.

For first time United Nations still in the early nineties put forward idea of sustainable development. But on way of performance of planned purposes there were certain difficulties, also world crisis of 2008 had negative impact. The ability to forecast future developments in geopolitics, ecology, socio-economics and determine strategic priorities for the world's economic development to ensure sustainable growth has become a prime concern since the crisis of 2008 (Yakovets, 2011). Unfortunately, this far no reasonable strategy for the development of the world's economy in the context of ongoing globalization has been offered. Global mechanisms of strategic planning remain rather underdeveloped. And this is a real disaster for all mankind. To elaborate the Concept of Strategic Planning for Global Social and Economic Development in UN World, it is expedient to make a multicountry order for large multidisciplinary research teams, corporations. Too many researches are devoted to world financial crisis. Without going into details, we will note that among scientists and experts there is an opinion that it is necessary to find uniform regulator of world currency that will make possible to plan a ratio between world production, consumption and a monetary covering, goods and services.

We made attempt to prove approaches to definition of uniform universal measurement of currency for whole world in form of "power", i.e. relation of kilowatt to currency $\mathrm{kW} /$ currency. It will allow to get rid of speculative capital not provided with real power. Briefly the essence of this question is in the following: Modern calculation of gross domestic product in dollars is incorrect from coefficient point of view for recalculation of various currencies. The power unit for example, kilowatt in Africa, and in America, both in 
Europe, and in Asia remains in kilowatt and therefore can and has to be used for establishment of exchange rate of currencies.

For this purpose we will present number of columns in table 1 (the countries, the population, economic opportunities): for Europe we will express the gross domestic product column in Eurozone currency, for USA in dollars, for Russia - in rubles, for Kazakhstan - in tenge and we will add one more which will express the cost of 0,1 watts in national currency. For simplicity of consideration we will take integrally economic opportunities are gross domestic product of the country expressed in gigawatts. Similar calculations can be carried out over any country of the world.

The algorithm of calculation it

1. to determine country power in watts (through electricity consumption, fuels and food).

2. to define Sq.m Unit ("quantity of money in economy"). For example, 10 watt $=1$ ruble/tenge.

Thus "sovereignty" of country isn't limited to any obligations. For example, to let out $X$ money in economy, instead of $Y$. But at trade operations between countries coefficient of recalculation of currencies will be connected with kilowatt. It somewhat return to when currencies had real filling by gold, now this filling by power on basis of power conservation law. For gold standard no physical conservation law existed.

UN in new quality has to control "cost" of all currencies of the world (filling by power), and not to allow formation of currencies which haven't been provided with assets. In this regard it is necessary to create expert currency commission and a single monetary union in the world (Sabden, 2011).

\section{Theoretical Model II: New Paradigm of 5-Hydrochloric Spiral}

In the context of the development of world civilization by societies we must build an innovative society is integral to the spiritual component, which will be funded by the synthesis of market and planned systems to absorb all the best accumulated by the world community, the previous formations until nowadays. In order to achieve this strategic objective, for different countries may different approaches should be used. For the Republic of Kazakhstan, our view, necessary to carry out a constitutional reform to move to system management authorities and to build it under the whole system of governance. It is necessary to put a largescale strategic task of building in Kazakhstan a new innovation economy based on the comprehensive modernization of the country, on new technologies, knowledge-intensive production sectors and modern scientific and technological achievements (Sabden, 2008). Of course, significant financial, human and material resources must be channeled into their development, reinforced by the stable political will of the leaders of our state with the power to manage the economy effectively.

As for specific government management actions, as an expert who has deeply studied the development of the world civilization, I can propose a new paradigm of state governance on the basis of the 5th helix. All fie components of innovation process design perform already more complex interrelated tasks, where the horizontal and vertical synergy functions of all five institutional segments of cluster education are intertwined. In this mechanism is a new paradigm of an integral innovation society and a new industrial revolution.

In Kazakhstan, a model is adopted in which the innovative economy is created by the government and business, i.e. through public-private partnership (PPP). But it is known from the experience of developed countries that it should be done together by the state, business and research universities (triple helix). In the $21^{\text {st }}$ century, the requirements of the world civilization, in our opinion, already need a 5th helix, i.e. interaction of the state, science, business, society and their information support. To accelerate the development of the economy, it is necessary to comprehensively master the priorities of the state's scientific and technical policy. We offer the basic elements of the concept of the "five-helix" (Figure 2).

Table 1: Economic opportunities of some countries in 2017

\begin{tabular}{|c|c|c|c|c|c|c|}
\hline Country & $\begin{array}{c}\text { Population, } \\
\text { mIn. ppl. }\end{array}$ & $\begin{array}{c}\text { GDP, } \\
\text { BIn.US\$ }\end{array}$ & $\begin{array}{c}\text { GDP per capita, } \\
\text { (US\$/person) }\end{array}$ & $\begin{array}{c}\text { Economic opportunities, } \\
\text { GWt }\end{array}$ & $\begin{array}{c}\text { Price of watt } \\
\text { power, US\$ }\end{array}$ & $\begin{array}{c}\text { Dollar support, } \\
\text { watts }\end{array}$ \\
\hline USA & 325,7 & 18036,65 & 56115,7 & 1117,2 & 16,14 & 0,062 \\
\hline EU & 508,2 & 16311,9 & 32004,9 & 834 & 19,56 & 0,051 \\
\hline China & 1390,0 & 11007,72 & 8027,7 & 1286,1 & 8,56 & 0,117 \\
\hline Russia & 136,7 & 1331,21 & 9092,6 & 307,1 & 4,33 & 0,231 \\
\hline Kazakhstan & 17,5 & 184,39 & 10510 & 27,7 & 6,66 & 0,15 \\
\hline Belorussia & 9,5 & 54,608 & 5740,5 & 12,5 & 4,37 & 0,229 \\
\hline Ukraine & 42,7 & 90,615 & 2115 & 52,4 & 1,73 & 0,578 \\
\hline
\end{tabular}


The concept of the "five-legged spiral" is represented in the form of a step-by-step transmission mechanism consisting of five blocks (gears), such as the state, small, medium and large business, research institutes and universities, as well as the needs of the human society and their information exchange. Here are the main functions of the blocks. For example, at the state level, the first bloc will adopt changes in the Constitution, constitutional laws and other legislative acts that ensure democracy and the balance of all branches of power. By forming a new structure of the three branches of power, the authority of the Parliament significantly broadens, with a simultaneous narrowing of presidential powers. It is supposed to ensure economic freedom and democracy on the part of legislative, executive, judicial and legal systems. The choice of policy will determine the capabilities of a country for an innovative and technological breakthrough. It is necessary to strengthen the government's competence in developing and successfully implementing strategic and tactical tasks of the country's economic development.

In the second cluster, a basic model of forced development of small and medium-sized businesses was developed, including 9 projects(Fig 3). The main goal in the near future is to form a middle class in the country, and make small business public property. In the interests of the people and economic development of the country, consolidation of various forces of society (business elite, civil society, NGOs, etc.) is needed.

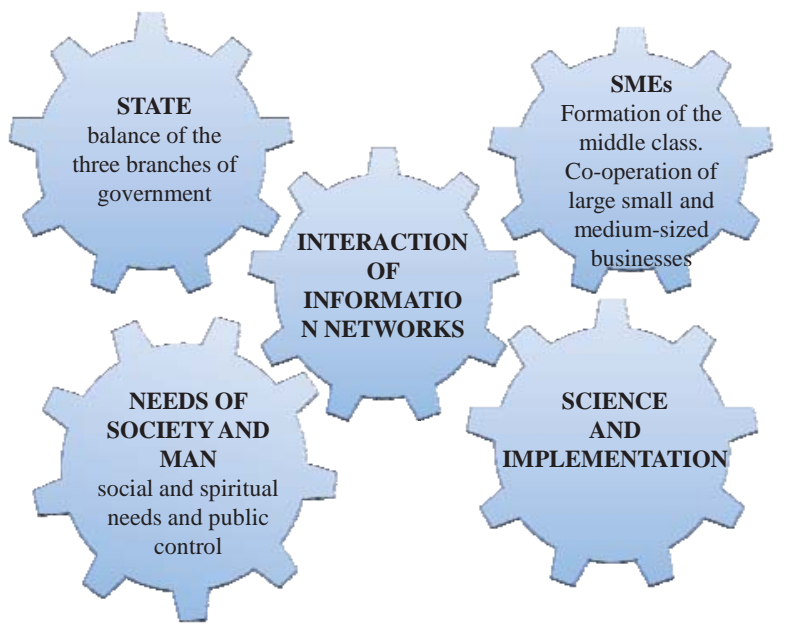

Figure 2: The basic elements of the "five-helix"

In the third block, there will be coordination of research institutes and universities, creation of technology parks, business incubators, small innovative enterprises, fundamental research of science and new knowledge, research and commercialization of their results in techno parks and production. It is essential to raise the share of research funding, $R \& D$ at the expense of entrepreneurial sector of the economy, which is very small. Created small innovative enterprises in research institutes and universities need to be released from taxes before the age of 3 years.

In the fourth block, various social requests for goods and services and other needs of the society will be formed, up to the individual orders of each person and legal entities. Especially it is necessary to revive the spiritual demands of society, which for years of sovereignty, market reforms remained on the margins of social development. Public control will be carried out through the newly created Public Chamber of the Republic of Kazakhstan for the implementation of laws, state and sector programs and projects, various state companies and holdings. In times of crisis, they should take seriously the issues of distribution of benefits for raising living standards. In this regard, the role of the third sector, i.e., civil society, will rise sharply, since with time it is through creative activity that will take a greater share in the social trust of state governance. Generating social capital comes first, and it is invested in markets and authorities.

The fifth block is entrusted with a very important task of engaging all components of state governance on the basis of the 5th helix. Here, through the formation of network communication, a database, sensory information flows, an effective functioning of all blocks of management links will be ensured. Figuratively speaking, in the implementation of this project, state management will be presented in the form of a closed technological cycle that provides a quality final product. We must admit that public-private partnerships (PPPs) and the 3rd spiral, that is, the borrowing of the state, business and science, have been effective so far.

\subsection{Business Driver of Economic Development}

In a crisis, when the economy undergoes a profound transformation, especially in the structural-resource aspect, the accelerated development of small and medium-sized enterprises (SMEs) can be the key to economic growth. In this regard, the entire economy of Kazakhstan should be transferred to a new track, because now the share of small businesses in GDP is according to different calculations of only $20 \sim 26 \%$. In developed countries, this figure reaches $50 \sim 70 \%$, and employment is provided up to $70 \sim 80 \%$.

In order to give a powerful impetus to the development of the economy of the Republic of Kazakhstan in the strategic plan and to solve the problems posed by the President of the Republic of Kazakhstan on joining the 30 developed countries, it is necessary to develop the Concept of the Strategy for the Accelerated Development of Small and Medium Enterprises. The vision of the concept is to turn 
small and medium-sized businesses into a key factor in transformational transformations in the country by actively involving the population in small business in the conditions of transferring the economy from the raw material model to the innovative one and forming the knowledge economy. Therefore, we have developed basic concept of the strategy of accelerated development of small and medium-sized businesses, including priorities, principles, objectives, and 9 projects that are focused on a qualitatively new innovation policy and a higher level of development of the national economy (Figure 3).

Project 1. Construction of a unified legislative system in the field of small and medium-sized business with the adoption of a new basic constitutional law "Business Code of the Republic of Kazakhstan" and in the context of this code the adoption of a number of laws that give a new impetus to the development of small and medium-sized business. To ensure the reduction of administrative barriers and streamline activity of controlling bodies, the Concept provides for the creation of a single regulatory and legal framework for ministries and departments, as well as regional authorities; the release of small innovative enterprises from the payment of corporate income tax (tax holidays) for two years of work, and the payment of $50 \%$ of the tax amount in the next two years; establishment of a simplified procedure for the liquidation of the MP.

Project 2. A radical change in structural policy in the sectors of the economy of the Republic of Kazakhstan with the maximum increase in the share of small business. In order to implement this project, measures should be taken to diversify the economy and mechanisms for increasing the share of IP in such industries as industry, including manufacturing, sphere, education, science, culture, art, literature, handicraft. It is universally necessary to create Centers for Production Support aimed at increasing the productivity of SME sector enterprises. Particular attention should be paid to the creation of a national network of scientific and technical intermediary firms that could ensure the rise of the national innovation system. For example, in China there are over 6 million such firms. In order to increase the efficiency of SMEs, the following programs should be implemented: financing for the development of new technologies; increasing the competitiveness of enterprises, ensuring the transition of enterprises to ISO standards.

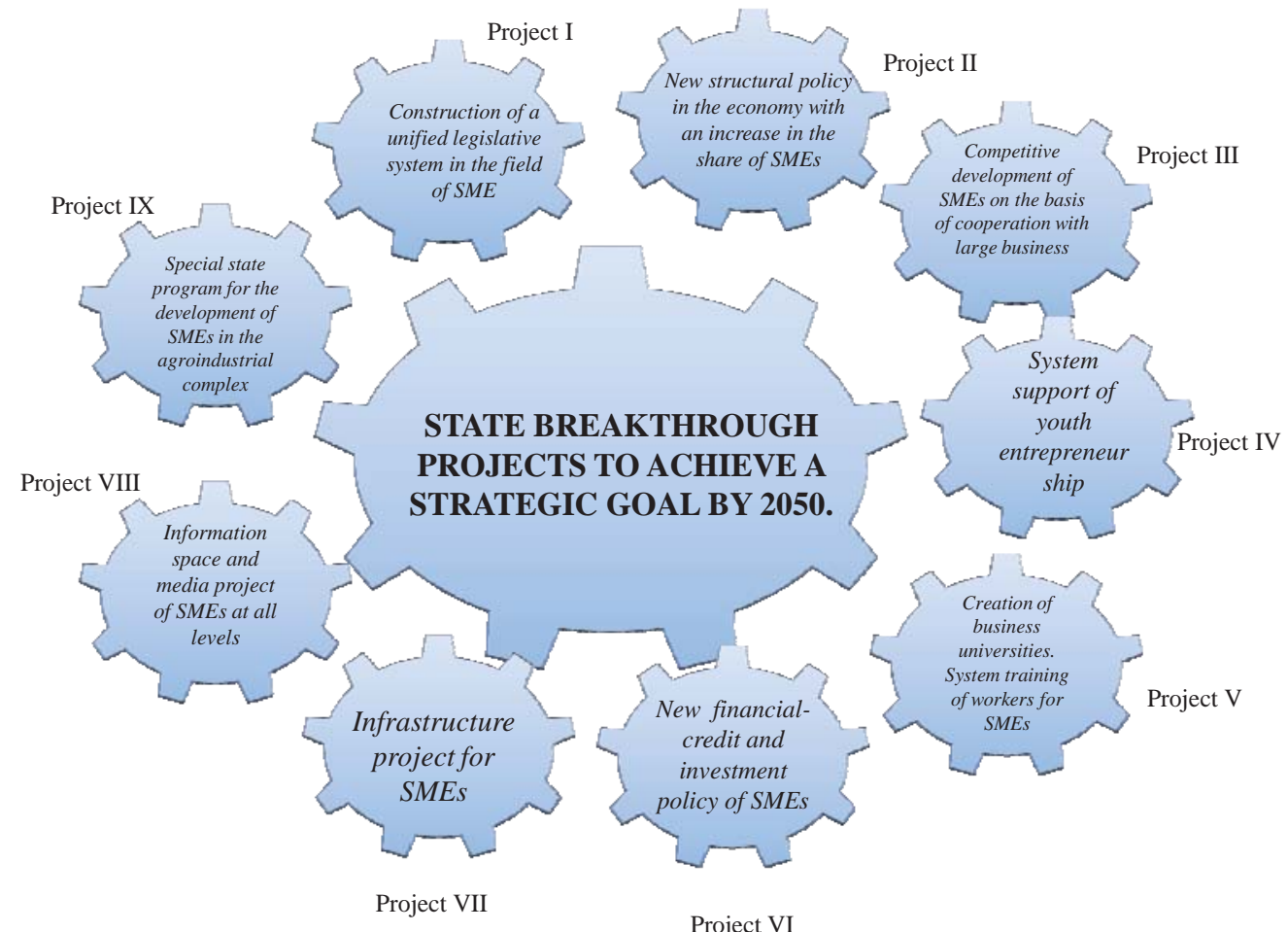

Figure 3: System for designing the forced development of small and medium-sized enterprises in the Republic of Kazakhstan 
Project 3. Competitive development of small and mediumsized businesses on the basis of cooperation, integration and clustering with large business, the development of subcontracting. It is necessary to establish the freedom to choose the organizational and legal forms of activity of small business entities, for which it is proposed to make appropriate changes to the Civil Code of the Republic of Kazakhstan. It is necessary to assist in the integration of small and large businesses, using the potential of enterprises in the process of restructuring industries and reforming enterprises. Create measures to stimulate enterprises and introduce mechanisms for production cooperation and subcontracting, including the placement of government orders to SMEs through tax incentives. In turn, large business in the process of cluster formation attracts SMEs for setting up production on the basis of close cooperation and subcontractual relations with active business and information interaction. As a result, a single technological process is built with a strong scientific, technical and production base.

Project 4. Systemic support and stimulation of youth entrepreneurship, the potential of which can give a powerful impetus to the development of the national economy as a whole. Taking into account that young people are the driving force of small business, it is advisable to implement qualitative changes in the formation and development of youth entrepreneurship in the Republic of Kazakhstan, up to the development of a separate State Program for the Development of Youth Entrepreneurship with the adoption of a framework law. In the youth environment, unfortunately, the entrepreneurial spirit is weakly expressed, presupposing readiness to take risks, create new ones. In this regard, foreign experience in creating international youth chambers, associations of MPs, unions of young owners of family enterprises and other associations, where leadership qualities of youth develop, social responsibility is useful.

Project 5. Development of entrepreneurial universities, training of professional staff for SMEs of a new generation. The implementation of this project implies the integration of education, science and business through the creation of innovative laboratories, where applied research will be carried out until an innovative product is obtained. In these structures, entrepreneurs are trained, while students are simultaneously trained and receive not only skills, but also a certain payment. In this regard, it is necessary to provide infrastructure support to universities and research institutes, the allocation of special grants and subsidies for research, as well as the formation of small innovative enterprises at universities and research institutes. In addition, it is necessary to create systems of additional education, professional retraining of entrepreneurs, including in rural areas.
Project 6. Development of new mechanisms of financial and credit and investment policy for the development of SMEs with the participation of foreign and local businessmen.

You must use a variety of methods and financing schemes: micro-loans, loans to cover large debt, venture capital, franchising, leasing, loan guarantees, subsidies, tax incentives, preferences, loans and bonuses in the first 2-3 years, MB, etc. as well as to adopt a law on the offshore funds for reinvestment in the economy, especially in small and medium enterprises in the Republic of Kazakhstan, ensure that investment and business forums for the presentation of business projects for private investors to support the MB.

Project 7. Infrastructure project to support entrepreneurship, transfer of the center of gravity to the local level. Increased public investment in infrastructure development and SME support will contribute to economic growth in the long term. This includes the development of an industrial and efficient transport and logistics infrastructure; modernization of the infrastructure of energy, heat and water supply systems; development of service infrastructure, local financial and credit infrastructure, infrastructure for retraining and employment of human resources in densely populated macroregions, where there is an excess of labor resources and the share of economic activity of the population is low. In general, the development of infrastructure projects creates the greatest multiplier effect for economic growth and employment due to the development of small business.

Project 8. Information space (Internet resources and telecommunications) and a media project to support the promotion of small business among the population.

It is necessary to provide information and consulting support to entrepreneurs on the basis of the current regulatory and legal acts. To provide consulting services in various areas of business, finance, taxation, accounting, personnel work, legal protection, business planning, advertising and other issues, it is necessary to open consulting centers in each city, district center, so that in the "one stop" mode a person could obtain all the exhaustive information concerning the conduct of business. A sectoral program "Information Program for SMEs" should be developed, which forms a unified system of information arrays to support entrepreneurial activity on the basis of modern methods and means of telecommunications and the Internet. This system will allow for the continuous exchange of information between SMEs and state support structures, monitoring of the state of SMEs, as well as the functional adaptation of SMEs to the needs of the economy.

Project 9. Special state program for the development of small business in the agro-industrial complex. The 
inexhaustible reserve for SMEs is people and the huge agricultural area of the country. Therefore, we specifically identified as a priority the development and adoption of a special state program for the development of small business in the agro-industrial complex, which includes the entire package of state support for the peasant economy and their cooperation, the development of agricultural infrastructure. The implementation of these projects may become a new driver for the accelerated growth of the economy of Kazakhstan.

\subsection{Science and Education Reform}

In the transition to an economy based on new knowledge, it is advisable to modernize science, education and healthcare, which will give impetus to the development of new technological structures. The development of world history shows that humanity has achieved high results and progress in its civilizational development. It is time to live comfortably, although it is known that over 1.2 billion people are hungry in the world (Keyns, 2011). Therefore, it is advisable to establish minimum barriers to normal life and the transition to an increase in the competitiveness of the creative economy in such areas of human capital as:

- health care (financing of health care on the recommendation of the World Health Organization should be at least 6\% of GDP);

- science (for the normal development of the state, the financing of science should be at least $1.5 \%$ of GDP);

- education (at least $6 \%$ of GDP);

- culture (at least 5\% of GDP);

- the formation of an intellectual economy, the creation of artificial intelligence;

- realization of the ideology of consumption of a competitive person and his standard of living (Rikardo, 2007).

The world crisis has exposed the negative consequences in the sphere of spiritual reproduction, socio-cultural civilization, in particular in science and education, culture and morality, moral values. The question is about the threat of moral degradation of society. One of the main features of this is clearly pronounced professional incompetence in all spheres of human capital, from the lowest level to the highest in public administration. This is especially evident in developing countries. Even developed countries during the crisis felt an acute shortage of personnel in risk management in the system of crisis management at the international level.

Hence a new paradigm of social innovation is born about an educated society, a person. In the context of the global crisis, it is education and science that come to the fore and become the basis of the whole system of the reproduction cycle, from the birth of ideas to the receipt of profits to meet human needs, as well as the launch of investment for a new civilization development. In this connection, the entire education system should be radically restructured, especially in the field of obtaining new knowledge, so that graduates of higher education immediately fall into the sphere of the process of reproduction, and not in the queue of unemployed with several diplomas.

All social spheres should work for spiritual reproduction, the reproduction of human capital, which as a result will significantly affect the innovation breakthrough. The main coordinators in this field should be such large UN entities as, for example, UNESCO, who must work out the Universal Declaration on the spiritual reproduction of the socio-cultural sphere, including education, culture, science and health, where it would be possible to establish acceptable threshold values for the criteria for increasing the competitiveness of the economy countries. These will be real steps into a new postindustrial social civilization. To determine these minimum socio-economic standards and further monitoring at the UN, it is necessary to create a World Expert Council. It is advisable for the United Nations to prepare a five-year Message to the Nations of the World, in which all that has been said can be reflected. The future of the world depends on the development of a new paradigm that guides the world's states and the world community towards the revival and multiplication of the spiritual and cultural potential of the world community. The task of world civilization is that it must again enter a state of innovative breakthrough on the basis of a new paradigm of the basic development of education, science and culture through a powerful investment in them. This will be the main application for the transition, i.e. to the first type of planetary civilization

\subsection{The Needs of Man and Society}

Ultimately, all the previous components of the concept of the 5th spiral work on the needs of society or, more specifically, on the needs to meet the vital needs of each person. The economy and production should be oriented towards meeting the needs of a non-abstract consumer, a particular person. Proceeding from this, only by establishing such minimum socio-economic standards (certain standards of life) in the field of human capital can we really ensure a comfortable life. By linking the minimum standards with the growth rates of the economy, it is possible to determine the standards of the level and quality of life for developing countries and third world countries. If these norms ensure high rates of economic growth, the standard of living of the population will automatically increase proportionally, depending on the abilities of the individual and the competitiveness of each person, the nation, the people and the country as a whole. 
As a result of a fair approach to all and every person on the planet, the same conditions will be created for ensuring peace and harmony, as well as increasing the competitiveness of countries. With this approach, there is a desire to equalize the conditions of functioning of citizens, the same opportunities for manifesting their abilities, as well as to bring together the living standards of various segments of the world population. Even yesterday, the frightening world, the exponential growth of the world's population is already changing to the opposite for most developed countries the question of depopulation, excess of death rate over birth rate. One should regroup its forces and resources, target civil society to unite the people. It follows from the foregoing that it is necessary to ensure maneuverability of resources and opportunities, to strengthen organizational measures to create a post-crisis economy and to monitor their implementation. Only in this case it is possible to achieve the effectiveness of crisis management and postcrisis state.

In connection with this, an important link in the management of the economy is the assessment of the appropriateness and usefulness of laws that are adopted by legislators, the reliability of communication between the center and regions, between citizens and the state. Thus, it can be achieved that society can declare the authorities about its interests and it will be heard. The realization of such a mission can be entrusted to the Public Chamber. In connection with constitutional changes, there is a need for an objective assessment of the process of managing the economy, the implementation of the decisions of the Government and, in particular, anti-crisis measures. It is necessary to direct civil society to the real participation and assistance of state authorities in implementing both strategic and current tasks of socioeconomic and political development of the country.

To overcome the crisis, the Public Chamber should become one of the main institutions of civil society, i.e. to give it a new status of functioning under the President of the Republic of Kazakhstan, as in Russia. Strengthening its status, the Public Chamber should become an open platform for discussing vital issues and adopting recommendatory or mandatory proposals for implementation, uniting in its ranks wide sections of civil society, including representatives of all parties.

With the emergence of the Public Chamber in the new status, the society can get the opportunity to control the power - executive and legislative. Independence and competence of the members of the Chamber will allow correctly assessing how effective the activities of the Government and regional authorities are, how correct, useful and useful are laws passed by legislators, the Public Chamber is expected to become a reliable link between the center and the regions, between citizens and the state. Troll lets you connect people to the best reserves zhizni. A society can declare the power of their own interests and will be heard.

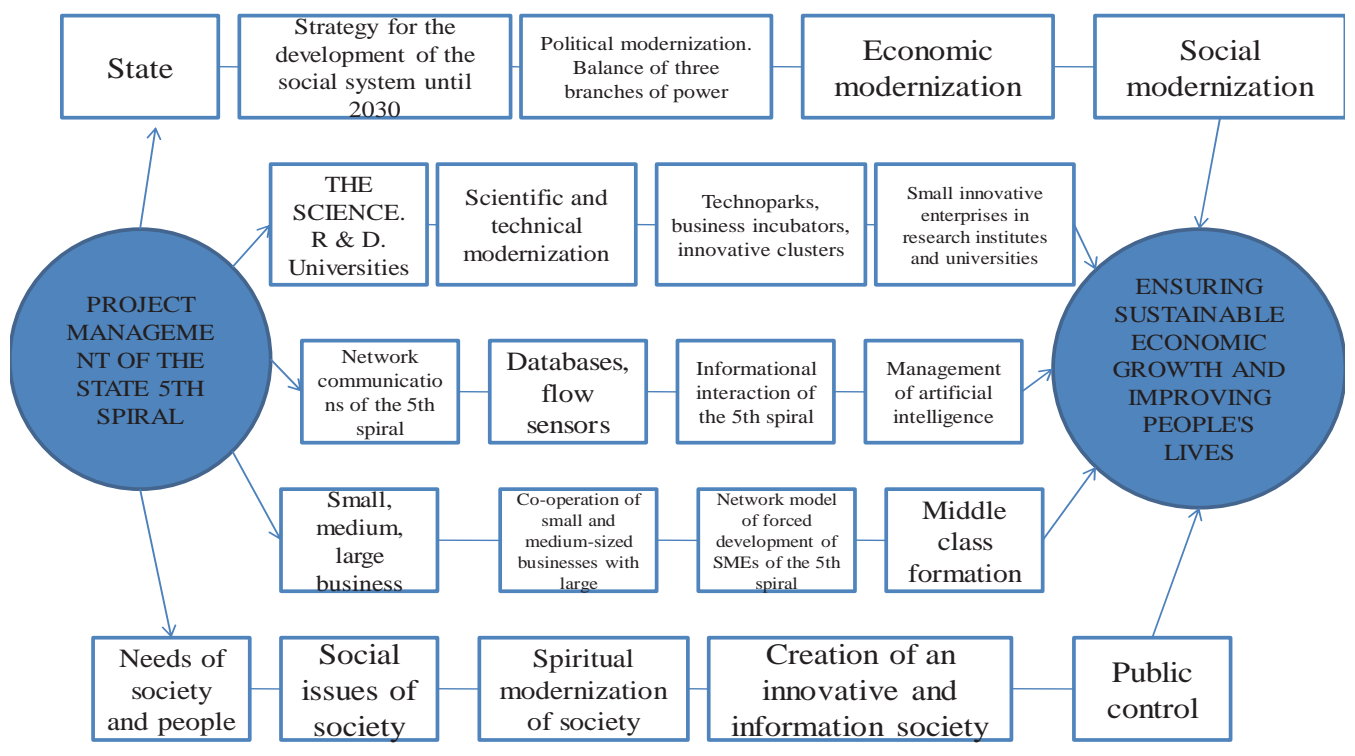

Figure 4: Network management of the state on the basis of the 5-th spiral 


\subsection{Information Support}

The fifth block is entrusted with a very important task of engaging all components of state governance on the basis of the 5th helix. Here, through the formation of network communication, a database, sensory information flows, effective functioning of all blocks of management links will be ensured. Figuratively speaking, in implementing this project of state management, it is presented as a closed technological cycle, providing a quality final product. We must admit that public-private partnerships (PPPs) and the 3rd spiral, that is, the borrowing of the state, business and science, have been effective so far.

But this approach and methods of state management based on the 5th helix are first introduced to the judges of scientists and the international community. More reliably in the world, network management of the state on the basis of the 5-th spiral, taking into account the important tasks in each block are shown in Figure 4.

\section{References}

Keyns, D. M. (2011). Return of the Master (in Russian). Moscow: Yunayted Press.
Kinsley, M., \& Clarke, C. (2010). Creative Capitalism (in Russian). Moscow: Popurri.

Moiseyev, N. M. (1999). To be or not to be humanity (in Russian). Moscow: Popurri.

Rikardo, D. (2007). The beginning of political economy and taxation (in Russian). Moscow: EKSMO.

Sabden, O. (2009). Economic selected works: I-XXV (in Russian). Almaty: Exclusive.

Sabden, O. (2008). Innovative economy (in Russian). Almaty: Exclusive.

Sabden, O., \& Armenskiy, A. (2011). Sustainable economic growth in the EurazEU countries based on the laws of development (in Russian). Almaty: Ekonomics.

Sabden, O., \& Ashirov, A. (2015). The concept of human development in the XIII century and food security(in Russian). Almaty: Ekonomics.

Stiglitz, J. (2009). Freefall: America, Free Markets Sinking Economy. Norton.

Subetto, A. I. (2013). Noosphere-scientific and spiritualmoral grounds for human survival in the XXI century (in Russian). St. Petersburg: Asterion.

Vernadskiy, V. I. (1991). Scientific thought as a planetary phenomenon (in Russian). Moscow: Science.

Yakovets, Y. U. V. (2011). Global economic transformations of the XXI century (in Russian). Moscow: Ekonomics. 